\title{
Taking Lessons from Silent Spring: Using Environmental Literature for Climate Change
}

\author{
Craig A. Meyer (1)
}

Department of Language and Literature, Texas A\&M University-Kingsville, Kingsville, TX 78363, USA; craig.meyer@tamuk.edu

\begin{abstract}
Rachel Carson's Silent Spring (1962) created a new genre termed "science nonfiction literature." This genre blended environmental science and narrative while ushering in a new era of awareness and interest for both. With the contemporary climate crisis becoming more dire, this article returns to Carson's work for insight into ways to engage deniers of climate change and methods to propel action. Further, it investigates and evaluates the writing within Silent Spring by considering its past in our present. Using the corporate reception of Carson's book as reference, this article also examines ways climate change opponents create misunderstandings and inappropriately deceive and misdirect the public. Through this analysis, connections are made that connect literature, science, and public engagement, which can engender a broader, more comprehensive awareness of the importance of environmental literature as a medium for climate awareness progress.
\end{abstract}

Keywords: Rachel Carson; Silent Spring; science; nonfiction; narrative; environment; climate change

check for updates

Citation: Meyer, Craig A. 2021. Taking Lessons from Silent Spring: Using Environmental Literature for Climate Change. Literature 1: 2-13. https://doi.org/10.3390/literature 1010002

Academic Editor: Lauri Scheyer

Received: 6 May 2021

Accepted: 20 July 2021

Published: 29 July 2021

Publisher's Note: MDPI stays neutral with regard to jurisdictional claims in published maps and institutional affiliations.

Copyright: (C) 2021 by the author. Licensee MDPI, Basel, Switzerland. This article is an open access article distributed under the terms and conditions of the Creative Commons Attribution (CC BY) license (https:// creativecommons.org/licenses/by/ $4.0 /)$.
No witchcraft, no enemy action had silenced the rebirth of new life in this stricken world. The people had done it to themselves. Rachel Carson (1962, p. 3)

\section{Introduction}

In 1958, Olga Owens Huckins wrote a letter to the Boston Herald, which described recent aerial sprayings of DDT near her home; she writes,

The "harmless" shower-bath killed seven of our lovely songbirds outright. We picked up three dead bodies the next morning right by the door. They were birds that had lived close to us, trusted us, and built their nests in our trees year after year. The next day they were scattered around the birdbath [ ... ]. All of these birds died horribly and in the same way. (qtd. in Williams 2007, "The Moral Courage of Rachel Carson", pp. 135-36)

Shortly thereafter, she wrote another letter to her friend Rachel Carson desperately informing her of the event and the dangers of pesticides. Huckins asked Carson if she could write something about chemical spraying and its harm on wildlife. What Carson wrote started a new genre of literature and started an environmental movement. As the sixty-year anniversary of Rachel Carson's Silent Spring nears in 2022, her text remains important as we consider the lasting effects of the $2010 \mathrm{BP}$ oil spill in the Gulf of Mexico, the nowannual devastating major hurricanes and wildfires, the ramifications of oil pipelines, and the push for green alternatives for everything from automobiles to the electrical grid. Although Carson's work focuses on chemicals and pesticides, many readers can connect and recognize the larger meaning of how humans interact and even misuse and abuse the environment. With this then-new genre, Carson sought to awaken governments, companies, and people who blindly believed nothing was happening to damage the world that we live in. Looking back across these sixty years, we come to realize that the realities are mostly the same; yet, we can consider Carson's work more critically now and take some lessons from it. 
Literature is part of our historical footprint for future societies and cultures to learn from so they can better understand how we were part of our world in our time. We have seen texts change a culture's thinking. One well-known example is Harriet Beecher Stowe's Uncle Tom's Cabin, which was rumored to be the book that started the American Civil War. Other authors such as Henry David Thoreau, Amy Tan, Plato, Upton Sinclair, Toni Morrison, George Orwell, Gabriel García Márquez, Jane Austen, and Frederick Douglass have shaped how we think and operate in the world, forced us to confront ugly realities, offered us hope about each other, and cautioned us about frightful futures. Carson added her name to this list with Silent Spring.

This article considers Carson's Silent Spring on several levels. First, Carson's narrative style is investigated along with what others claim she uses. This new genre of literature that blended science, literature, and narrative to create an informed readership was proven effective because of Carson's credibility and experience. With Carson as guide, readers could act with new knowledge of the dangers of pesticides and other chemicals. They would learn about the science and then understand it through the narrative. It was Carson's hope that public and political pressure would create new laws, regulations, and protections, and this goal was partly realized. Second, the timing of Silent Spring provides insight into the need for this new genre as well as its effectiveness for that time period. The period provided ample opportunity to generate a range of emotions, but Carson focused on providing readers the facts, which leads to the third section. Carson needed to be certain her research was accurate and accessible to layperson readers. She recognized the influence of the large, powerful companies and corporations that were producing and selling these deadly chemical poisons and how they would respond to the truth being made available to the public. The latter parts of the article focus on the use of emotional appeals by Carson and in relation to the climate change discussion. While Carson suggested a solution of radiation, offered in the last chapter, she provided it while not knowing its outcomes and relying on the hopes and fears of readers, which seems uncharacteristic in relation to the rest of her work. Finally, this article focuses on that hope in relation to where we are presently in the environmental/climate change "debate" and some of the serious concerns of how strong, well-researched texts such as Carson's serve as insight moving forward. In doing so, the conclusion points to the ways science and the idea of fairness have been distorted at the expense of progress and possibly saving lives. In the end, the realization becomes clear: the human race will either begin to right the wrongs we have done to the planet, or we will continue to make haphazard, feeble, and inadequate attempts to do so, which will ultimately and slowly make the planet inhospitable for life-human life. Books such as Carson's, that is, well researched and narrative driven, offer a way to communicate effectively to the public in order to drive meaningful action on the climate crisis.

\section{A Literary Genre for Its Time}

Like Truman Capote's In Cold Blood, Silent Spring created its own genre, which might be termed "science nonfiction literature" (Killingsworth and Palmer 2000, p. 175). This science nonfiction literature of hers follows some tenets of fiction writing and storytelling, but also the logical reporting of data common in scientific writings. Even though Carson titles her opening chapter "A Fable for Tomorrow", she prepares readers, to some degree, for a fictionalized but realistic tale. Conservationist, activist, and author Terry Tempest Williams refers to her work as "storytelling" (Williams 2008, "One Patriot", p. 18). In fact, some writers have likened Carson to the Romantics (Lytle 2007, p. 134). Although not as idealistic as some Romantics, she does take another route to understanding through emotional appeal and child-like wonder; however, she turns this quickly as chapters progress to a litany of reports about the use of deadly chemicals, pesticides, and toxins. Considering her text deeper, Carol B. Gartner, a biographer of Carson, explains that Carson created a blend of "science and literary art so seamless that the effect is seductive" (Gartner 2000, p. 103). The scale of seduction derives from the science and the fictional imprints, which are balanced by the amount of real data gleaned from hundreds of sources 
(not unlike what the realities of climate science tells us). Carson's story becomes more evident with her continual "use of recurrent themes, motifs, and images" that are mainstays in fiction writing (Gartner 2000, p. 104). Carson, who had already established herself as a best-selling author with her earlier works, understood the dynamics of telling a story and the "poetic technique" behind combining complex material with realistic scenarios (Gartner 2000, p. 105). The knowledge of storytelling was certainly in her arsenal since she studied literature at Pennsylvania College for Women and underwent a "struggle to decide whether or not to change her major from English to biology" (McCay 1993, p. 5). Obviously, she chose the latter but maintained the usefulness and proficiency of the former.

Carson also presents her text relative to the events of the period and the growing realization of oft little studied or understood chemicals that were being introduced to our communities (and still are). The timing of Silent Spring certainly was on target, because we see the waves of change that it helped usher in, such as a governmental review of pesticide usage and her last public appearance for testimony at one of President John F. Kennedy's Science Advisory Committee meetings. Her credibility was partly established by Carson's earlier works and their respective popularity, most notably The Sea Around Us. Her experience at the Fish and Wildlife Service proved a pivotal benefit to Silent Spring because of the information available and the numerous contacts she developed. While there, she was encouraged by the reception of her writings and did eventually leave to pursue her writing. Nevertheless, people knew her name and were probably familiar with her work. On the first two pages, by creating the scenario of some "strange blight", some "evil spell", and presenting the "shadow of death", Carson creates a vivid, emotional, even frightening, connection to readers that offers a reality they are unprepared for-their own demise through often unseen, untouched, unheard, untasted, or even unsmelt bits of death magnified by repeated exposure (Carson 1962, p. 2). Carson crafts her argument through reason and evidence, which is woven throughout the text. Obviously, the multiple references to studies, interviews, and other gatherings of scientific knowledge strengthen her argument, and they take up over fifty pages of references.

However, some scholars, such as Joseph L. Bast, Peter J. Hill, and Richard C. Rue authors of Eco-Sanity: A Common-Sense Guide to Environmentalism, argue against Carson's evidence, "Though the language of Silent Spring has more in common with Night of the Living Dead and Frankenstein than it does with a scientific treatise, the book was presented to the public as objective science" (Bast et al. 1994, p. 36). The problem with Bast, Hill, and Rue is that it appears they only read the first few pages of Carson's text. Silent Spring was not just a scientific book, but her text did certainly have scientific characteristics, which at times make it read as such. Associate Professor of Sustainability at the University of British Columbia, Greg Garrard illustrates that Carson "undertook cultural not scientific work" (Garrard 2004, p. 6). He contends, aside from the scientific information, Carson presented a societal and cultural problem, which happened to include science (Garrard 2004, p. 6). Of course, Carson does present a text that has apocalyptic undertones at various points, but such currents do not take up the bulk of the book. These undertones help engage the reader by feeding off the news of the time and presenting it into understandable, relatable bits for readers. This genre creation utilized elements of literature and science to engage readers instead of dumping piles of scientific studies in their laps.

\section{The Use of Fear}

In 1961, U.S. President Eisenhower warned of the "military-industrial complex" in his farewell address, and the nation was already embattled in the Cold War and the stockpiling of nuclear weapons-so many that the Earth itself could be destroyed dozens, if not hundreds, of times. Even E. B. White, the great essayist and author of the award-winning children's novel Charlotte's Web, demonstrates concerns about nuclear warfare: “The Hbomb is an extremely effective deterrent to war, but it has little virtue as a weapon of war, because it would leave the world uninhabitable" (White 2008, p. 332, original emphasis). The saber-rattle of an atom bomb certainly could create feelings of fear in foreign lands, and 
the hope was (and is) to engender compliance. This type of discourse created a certain level of fear and trepidation within the populace, even given the many advances of modernity.

Understanding a similar moment, Carson utilized this disaster narrative, radioactive fallout, and annihilation and, in so doing, reported the reality of how humans were stressing, perhaps destroying, the ecosystem that provided and maintained our lives. The popularity of her text makes sense based upon the skittishness of the populace and even people's hunger to be frightened. This nervousness is partially derived from events taking place during that period such as the Bay of Pigs, the decolonizing of Africa, the Civil Rights movement, the construction of the Berlin Wall, nuclear scares, Idaho Falls, and the early stages of the Vietnam War. Now, as we have moved through the twenty-teens, there is a resurgence of her work partly because that same sense of apocalypse has returned. We have seen massive oil spills, wars over water, multiple major hurricanes year after year, massive wildfires on the American west coast, increasing severe droughts, and an almost unintelligible "debate" about the realities of climate change. The chemicals Carson's friend wrote to her about could easily be swapped out now for record strings of 100-degree days or having to use the Greek alphabet to name hurricanes (which has only happened twice, 2005 and 2020). With these new realities of yearly catastrophic events, Lisa H. Sideris and Kathleen Dean Moore, editors of a Carson biography, suggest that "Carson's work appears remarkably relevant and even prescient" (Sideris and Moore 2008, p. 2). Williams, too, upon first reading Silent Spring, notes how she "was struck by how little had changed. Each page was still a shock and a revelation" (Williams 2008, "One Patriot", p. 17). Carson's work does seem to have a timeless quality to it, because we have mostly ignored the warnings that she has provided because of a false dichotomy of fairness to climate deniers-a point that will be returned to later. Moreover, our culture seems to react to and gravitate toward fear-based rhetoric, which Carson utilized.

There are a few competing theories about the strategy of Carson's Silent Spring. First, by environmental authors Jimmie M. Killingsworth and Jacqueline S. Palmer, who suggest Carson uses "a kind of apocalyptic narrative" (qtd. in Waddell 2000, p. 8). Most readers can pick out this reading easily because of the scary picture of the potential future Carson creates with her words. In randomly opening to a page of Carson's book, the following passage was found:

as the planes went about their work [of spraying pellets of aldrin, a chlorinated hydrocarbon and poison, in an attempt to wipe out the Japanese beetle] the pellets of insecticide fell on beetles and humans alike, showers of "harmless" poison descending on people shopping or going to work and on children out from school for the lunch hour. (Carson 1962, p. 91)

Obviously, the terrifying nature of this sentence does not go unnoticed by most readers. In fact, most people can envision themselves or their children outside when these low flying planes descend with millions of little pellets falling all around them-who would not think it is some kind of attack, especially after the events of September 11th? Certainly, other events would raise concern for original readers; perhaps the 1960 spy planes the Soviets shot down or the collision of United Airlines and TWA planes in New York City or even still the largest hydrogen bomb explosion detonated by the Soviets-so yes, there was precedence for concern of low flying planes, then and now.

Whereas Killingsworth and Palmer believed Carson was the one creating the apocalyptic scenes, Craig Waddell, Associate Professor of Rhetoric, provides another option. Waddell focuses his attention on his "zeitgeist thesis", which he describes as "[Carson's] ability to allay concerns with the spirit of the times" (Waddell 2000, p. 9). As noted, one concern of the 1960s was nuclear war and life on Earth's complete destruction (some may recall hearing or participating in drills that had little Johnny hiding beneath his desk in hopes of averting nuclear fallout). Waddell's point refers more to the popular concerns of the day, war with the Soviet Union, nuclear holocaust, etc. Further, he believes Carson utilized the then-current fear and concerns of Americans to emphasize her point. By reading the text, we can see, even based on the random selection above, both theories functioning 
well. One benefitted from the attention of fear and the other the time period. This dance between themes is mirrored in the current "debates" about climate change: one side has demonstrated that we must act; the other wants to believe it is not real. Both ignore the evidence.

Nevertheless, the Killingsworth and Palmer theory functions based on "contrasts" and "conflicts", as noted by Waddell (Killingsworth and Palmer 2000, p. 9). This is evident by two main aspects of the selection. Initially, mechanical planes, not the pilots flying them, are dropping their deadly cargo. In contrast, the poison is being dropped on animate humans and wildlife. Modern readers might recognize terms such as greenhouse gases or melting icebergs in contrast to the humans generating the gases or the cause of the melting bergs. The other conflict is the sense of freedom and autonomy that is being ripped away by those machines from unsuspecting, law-abiding citizens and their responsible, school-attending children. The focus here is on the nouns: planes, work, insecticide, people, children, school. The nouns create the sense of normal life, which Carson switches to create an apocalypse. The abstract nature of freedom, too, provides a string that tugs at readers' sense of individuality and self-preservation, but not their collective responsibility to each other.

Waddell, too, focuses on the actual words Carson uses, but different ones. Since the fear of nuclear annihilation (that is, nuclear bombs falling or descending to earth) was a major fear of many Americans, Carson, via Waddell's theory, emphasizes this metaphor. Again, two main aspects of this metaphor come to mind. First, the obvious one just referred to-nuclear war. Most Americans may have reasoned that the Soviets also had planes that could deliver nuclear weapons on American soil like our B-52s of the era. By just a shift of words, radiation for insecticide perhaps, we can see how this fear may create some level of panic: radiation fell on beetles and humans alike. This slight adjustment changes the entire impression of the sentence and gives it a much more dire consequence. Secondly, readers may envision descending in Biblical terms, as in descending to hell. The folklore suggests a place that is rather inhospitable. Couple that impression with normal, everyday citizens and their children being subjected to such a place.

Carson did use both of those theories, but also two others. The easiest to explain of these is, as Tarla Rai Peterson and Markus J. Peterson assert, that Carson represents "most human supporters of chemical warfare [against insects] as ignorant rather than inherently evil" (Peterson and Peterson 2000, p. 80) (Alas, we see the connection to climate change again). Another important aspect of Carson's text rests in the impression that she rarely mentions or attacks the manufacturers of or people behind the deadly poisons she describes throughout the book. She avoids the potential trap of ad hominem attacks in hopes of eliciting productive responses. She does, however, name many types of chemicals and what research she has uncovered about their respective damage to wildlife and human life. There is little doubt that Carson knew the names of people and companies considering the depth of her research and clear understanding of the topic and its players. This tactic is used in our current "debates" about climate change and the settled science but in a different way. Conservative pundits point to liberal scientists as furthering some agenda, but avoid naming the scientists or the agenda, just pointing to a need for "fairness" to their misguided and unsupported thinking. Carson, nonetheless, seems to go out of her way not to mention names of companies and supporters of chemical treatments against flora, insects, and animals. This decision is wise since she does not want to point these entities out because it is easier to make adjustments rather than be pointed at, and then make adjustments. Carson knew her text would create a firestorm, but she wisely concluded the adjustments would be easier to deal with if she was more tacit in her attack-the guilty parties would know they were in fact guilty and hopefully could take more appropriate actions silently. We see this hope in regard to climate change too; with overwhelming evidence of climate change and its effects, the hope that companies and countries will take actions to mitigate and manage it. We know this approach has been only marginally effective. With her story, Carson used precise facts, somewhat like historical fiction. She used the tools of literature 
to engage readers and engaged readers remember the details more vividly than unengaged ones. Yes, there was creativity in presentation and narrative. Yes, she had to convey large amounts of stoic, scientific data to inexperienced and nonscientific readers. Yes, she had to keep them reading. And she did this by giving them the facts.

\section{Just the Facts, Ma'am ...}

Anticipating the importance of Silent Spring and its ramifications and bringing a focus on the evidence, Carson became an expert in chemicals, the use of pesticides and herbicides, and their effects on insects, fish, birds, other wildlife, and, most importantly, humans. Yet, she explains in a speech to the National Women's Press Club, "I have never asked the reader to take my word. I have given him [sic] a very clear indication of my sources" (qtd. in Lear 1998, p. 207, original emphasis). Her work at the Fish and Wildlife Service provided her with tremendous access to the science, the journals, the experts, and the stories she details in the book. Graham confirms that Carson did indeed comb "through thousands of scientific papers and articles" to gather her evidence and form her judgement (Graham 1970, p. 27). This judgement helped her realize potential outcomes, such as the naysayers saying she was wrong or not enough research had been conducted yet. Not surprisingly, Carson knew she would be attacked based on the rumors of her text and constructed her text to be, as she explains, "on an unshakable foundation", which she wrote to her editor, Paul Brooks (qtd. in Graham 1970, p. 32). This realization forced her to add additional years to her writing schedule. Although her health was weakened due to cancer and her mother passing away surely slowed her writing, Carson saw a change of "character" in humans' use of power as it related to the environment, and she endured (6). Her endurance forced chemical producers and their supporters to take notice and resulted in several smear campaigns against her.

Even before publication, Velsicol, a chemical producer, sent a letter to Silent Spring's publisher, Houghton Mifflin, arguing that Carson's book would be unfairly attacking the chemical industry (Graham 1970, p. 49). Houghton Mifflin responded and asked for "detailed information", with which Velsicol obliged (Graham 1970, p. 49). Carson's publisher, then, took her text and the concerns of Velsicol to "an independent toxicologist to review the disputed material" (Graham 1970, p. 49). After the materials were reviewed, Carson's material was "confirmed" as being accurate and "nothing further was heard about the matter" (Graham 1970, p. 49). Others also sought to undercut Carson's work with numerous interviews and news releases aimed at discrediting her and her work, even to the point of highlighting her gender (in hopes of suggesting a woman could not offer credible scientific information) and referring to her as a "Communist" (Hynes 1989, p. 41). In her speech at the National Women's Press Club, she understood the backlash and playfully referred to a trade magazine's hopefulness at the timing of Silent Spring's publication, that being in the fall, would be beneficial in that by spring her work would be forgotten (Lear 1998, p. 215). Unfortunately for them, it was not. More importantly, Carson provided her readers with the facts, the evidence, and everything they would need to decide for themselves.

One can continue to be dumbfounded by the fact, even with Carson's fifty-five pages of references, conservatives James R. Dunn and John E. Kinney could conclude that "the threat of pesticides to bird life are precisely the opposite of reality" (Dunn and Kinney 1996, p. 222, my emphasis) and that "Carson's major conclusions were incorrect" (Dunn and Kinney 1996, p. 194). Indeed, Dunn and Kinney liken Carson to Hitler (!) through the use of select sources (Dunn and Kinney 1996, p. 194). Yet, earlier in that same text, Dunn and Kinney concede, "Of course, pesticides are poison [ . . and] insecticides, like any poison, can be dangerous" (Dunn and Kinney 1996, p. 57). These observations do not seem to follow. If these chemicals are poisons, how could Carson's conclusions be mistaken? The term conclusions might suggest one person's, in this case Carson's, belief that $\mathrm{X}$ will bring about $\mathrm{Y}$. Carson illustrates, repeatedly, results of chemical usage across the landscape. Carson refers to hundreds of studies and scientific evidence to craft the 
narrative. In short, the "conclusions" are not conclusions; they are consequences. Still, over and over, Dunn and Kinney cite "Carson's major thesis was exactly 180 degrees in error" (Dunn and Kinney 1996, p. 58). Even then with pesticides, like now with climate change, the writing was on the wall and as clear as could be for an objective readership.

Author of Beyond Environmentalism: A Philosophy of Nature, Jeffrey E. Foss, like many others, believes that Carson "proved once and for all the folly of pesticide use" (Foss 2009, p. 71). This feeling seemed to stick to Carson after a 1963 episode of CBS Reports where she and Dr. Robert White-Stevens both appeared. Stevens, a strong and vocal opponent of Carson, alleged that her text "was littered with crass mistakes" and that she promoted "world famine" (Hynes 1989, p. 126). However, Carson's calm demeanor ruled the day as she focused the discussion on the evidence and its logical consequences. J. E. de Steiguer, a specialist in natural resource policy, points out that shortly after CBS had Carson on air, a report was released by the U.S. Office of Science and Technology, which "amounted to official scientific endorsement of Silent Spring" (de Steiguer 1997, p. 39). As the government acknowledged the reality of the text, so did various officials in other departments such as the Department of the Interior. One official admits, "it became obvious that she [Carson] was many, many times better informed than her critics ... because she approached the problem from the viewpoint of basic science" (qtd. in de Steiguer 1997, p. 39). In other words, Carson asked, "What if ... " and "What's the effect?" when no one else did, then wrote the narrative to support it. In writing the narrative, she used the scientific evidence to provide the details of the logical results represented by the science. We have seen the same narrative told about climate change and the dire outcomes that will, and are, resulting by our inaction.

Even as many critics suggested that Carson was against the insecticides and herbicides running rampant in our ecological playground, she believed that they could be put to effective use, but within reasonable, researched limits. The litany of examples, articles, and other experiences did seem to warrant a complete stoppage of chemical and pesticide usage. And although Carson did understand the effects of chemicals, her other suggestions for the future do not appear to be as clear, nor as well researched, and certainly not as well thought out. And this is where we can learn more about how to better attend to the reality of our climate emergency.

\section{The End Folly}

Up to this point, pains have been taken to demonstrate how much energy Carson put into providing evidence and drawing conclusions and crafting a narrative in line with that evidence. Without equivocation, Carson wrote a shocking book about the use of insecticides and herbicides. Silent Spring scared readers into believing that chemicals might be the things that destroy all of humanity, as the insects simply evolve and adapt-and then, take over. Although Carson did not want to completely eliminate the use of these poisons, she did seek to severely curtail their usage. In the opening chapters of Silent Spring, Carson writes sentences such as, "In this now universal contamination of the environment, chemicals are the sinister and little-recognized partners of radiation in changing the very nature of the world - the very nature of its life" (Carson 1962, p. 6, my emphasis). When reading this sentence, consider what is being stated; Carson enlightens readers about how various chemicals are introduced into our environments as a means of "changing the very nature" of them. Further, she couples these chemicals with radiation-a telling move to be sure as readers consider the dangers of it and, as noted earlier, the Cold War, along with the-then threat of nuclear holocaust. She clearly informs readers that chemicals and radiation are altering nature and not for the benefit of it, or us.

Carson, undaunted, continues to cite example after example of instances where chemicals have killed birds, fish, and other wildlife. She, further, details times when humans took ill and even died because of the spraying or release of chemicals. Further still, she crafts detailed scenarios, most notably the first chapter, where "a strange stillness" fills the landscape where readers envision a dire, desolate place unfit for life (Carson 1962, 
p. 2). For more than 250 pages, Carson continues on this path of apocalyptic detail—citing hundreds of studies in support of her narrative. In so doing, she is unrelenting in her quest to demonize chemicals using the phrases familiar within the culture of nuclear doom. However, her final chapter seems to be the most critical, and where she falters. The mistake Carson makes is that she fails to offer support for her proposed solutions and instead relies on circumstantial evidence and conjecture.

Carson opens her final chapter with, "A truly extraordinary variety of alternatives to the chemical control of insects" (Carson 1962, p. 278). Some have had "brilliant success" and others are "ideas in the minds of imaginative scientists" (Carson 1962, p. 278). Carson seems to believe that scientific imagination will suddenly come forth and manage the problem. She, too, provided some odd suggestions. Frank Graham Jr. explains, Carson "was particularly interested in biological controls" (Graham 1970, p. 22). Later, he explains Carson sought to "attack the pests by artificially introduced diseases, predators, and sterilizers" (Graham 1970, p. 54, my emphasis). In other words, her grand solution is an artificial means of control; the very thing she has been warning readers against thus far in her book. Obviously, this is Carson's greatest blunder. Carson, for nearly three hundred pages, has hammered readers over the head with how much of a problem we have created by trying to control these assumed pests with chemicals - an artificial means of control. Now, she tells us that by coupling "attractants and poisons" (that is, chemicals) we may achieve reasonable results at control (Carson 1962, p. 287). Yet, it is not control-it is elimination. In her final chapter, whole regions of certain insects have been wiped out by her citing of instances where such measures have been used. However, she offers no study investigating the ecological impact of the loss of any particular insect or any other creature that will fill its place in the ecosystem.

Carson continues and suggests the use of ultrasound to kill mosquito larvae, and she even warns, "however, it kills other aquatic organisms as well" (Carson 1962, p. 288). Reminiscent to the same concerns she highlights earlier, repeatedly, a method of elimination will go beyond its intended purpose and kill other life not targeted. Astute readers will ask what will fill that human-created hole in the ecosystem, for which Carson provides no answer. If that were not enough, Carson suggests that maybe "introducing parasites and predators" will be more reasonable. To demonstrate, she points out the potential of introducing the "forest red ant" to North America-a species not native to North America (Carson 1962, p. 293) (A quick investigation into said "forest red ant" led me to Formica rufa, which Carson does not mention. But in her text, she does discuss studies from Germany, which is where Formica rufa is found natively. My assumption is that this is the ant Carson refers to in her text). Again, she carefully explains how "a youth corps from the local school, children 10 to 14 years old" could maintain these ant colonies and how simple, cost effective, and easy this solution appears (Carson 1962, p. 294). Yet, again, she provides no evidence to show the long-term effects of such introductions or on other life in these areas. These ecosystems could be put at extreme peril if more invasive, more parasitic, and more disastrous life forms were allowed to take hold. For example, Asian carp and the White Poplar are two invasive species that choke out native fish and trees and do not have native equals, so they thrive, while eliminating the native species. In other words, Carson presented a solution without the unequaled acumen she used to such great effect throughout much of her narrative.

However, there is one aspect that is even more disturbing: sterilizing insects with radiation. (Remember the dangers of radiation Carson noted earlier?) Carson seems initially cautious about using the term radiation, so she opts for "X-ray" instead-a more innocuous term to be sure (Carson 1962, p. 279). However, E. B. White, again, before Carson's book was published, writes, "All radiation is harmful, all of it shortens life, all is cumulative, nobody keeps track of how much he gets in the form of X-rays and radiotherapy, and all of it affects not only the recipient but his heirs" (Carson 1962, p. 331). Even with her well-researched lens, Carson focuses on studies and experiments that have sterilized vast amounts of certain types of insects-notably, the screw-worm fly and the tsetse fly. 
Only after almost three full pages of how miraculous sterilization by radiation is, does she actually use the term "radiation" (Carson 1962, p. 282). That is, after, she has explained how beneficial such measures are and provided examples of its effectiveness.

To be clear, she began and utilized throughout her text apocalyptic, nuclear holocausttype scenarios, and one of her solutions was radiation. Based on her own words, this was not a fully tested option compared to other ill-conceived options already described by her own work. The solution she provides appears to be just as foolhardy as dumping chemicals wherever a displeasing insect happens to arise. The point, then, is if humans introduce such imprudent measures, how is this different from the chemical sprays she is arguing against using? There are an unlimited number of variables most people cannot account for such as a disease or a predator introduced to a biosphere where its natural vaccine or enemy has been wiped out. What happens then?

Sadly, this radiation and tampering solution corrupts her position, because we should not repeat the same mistakes over and over again-we must learn from those mistakes, which Carson makes clear throughout her work, but then fails to follow through with in her final chapter. However, the critique of Carson's radiation solution should be placed in a broader context of her life. In 1960, a few years before Silent Spring was published, in the midst of caring for her ailing mother (who died that year) and embroiled in detailed and complex reading of scientific articles, Carson found out she had breast cancer. She started radiation treatments, which may advocate for her misguided use of radiation as a solution. Indeed, it appears it was her solution to simply stay alive. Further, one might suggest Carson could have been pressured (by herself or her editor) to finish the text and come up with some solutions_-good, bad, or indifferent. In considering this possibility, one might wonder, if Carson's health had been a bit better, what she might have come up with to replace the chemicals, the radiation, or dealing with the intrusion of nature? One can only speculate. Regardless, we can acknowledge this insight as we continue discussions about climate change and focus on the hopeful elements of the genre.

\section{Taking Lessons and Hopeful Conclusions}

The evidence proving climate change is convincing. Jay Michaelson confirms, "From 1998 to 2002, [ . . . ] the scientific press featured 928 articles supporting or showing evidence for anthropogenic climate change and zero opposing it" (Michaelson 2013, p. 230). However, he continues, during that same period, " $53 \%$ of newspaper stories in the New York Times, Washington Post, Los Angeles Times, and Wall Street Journal during the same period offered spokespeople on 'both sides' of the 'scientific debate'" (Michaelson 2013, p. 230). In other words, the scientific evidence proved convincing, but the reporting (one might say narrative) of the science was skewed towards the idea of presenting "both" sides of settled scientific evidence. The willingness to be objective about climate change created an inability to report about climate change. This created a stalemate between personal and societal responsibility. More importantly, this stalemate has shown a deference to inaction that has allowed several stopgaps to blossom. To better understand these stopgaps, William R. Freudenburg, Robert Gramling, and Debra J. Davidson conducted a study of SCAMS, which is an acronym for "'Scientific Certainty' Argumentation Methods." In their research, they recognized how easily science could be misconstrued to represent data as well as deceive people in believing that unless every scientist agrees the obvious conclusion must be wrong. They write about regulations based on scientific consensus:

the most important factors [ ... ] may have less to do with actual levels of scientific certainty or prestige than with the ability of politically skilled actors to construct and maintain the belief that science should mean absolute certaintyand that in the absence of 'scientific certainty,' no regulations should be put in place. (Freudenburg et al. 2008, p. 5)

This impression of uncertainty, while false and misleading, provides an opportunity to exploit our notion of fairness. Leah Ceccarelli points out that the public often accepts the idea "that there are always two sides to a debate", which is also reflected in news reporting 
and "leads to the views of a few maverick scientists often getting as much attention" as the mainstream ones (Ceccarelli 2011, p. 205). This imbalance creates an unrealistic view for the public and suggests there is "disagreement" (Ceccarelli 2011, p. 205). Ciccarelli explains the "values of fairness and freedom are exploited by those who manufacture a scientific controversy for public consumption in order to force scientists to enter a balanced public debate on a scientific claim that has already been decided in the technical sphere" (Ceccarelli 2011, p. 207). This value of fairness is used to create controversy where one does not (really) exist in scientific circles, and when those that ignore the evidence of the voluminous studies are not given equal time, they claim favoritism and unfair treatment as the facts are ignored. In short, the focus diverts to the idea of fairness and freedom and not the real issue and real evidence. There are few better examples of this than the discussion about climate change. These diversions act as a call of the oppressed "other" and the proverbial "underdog", which, then, engender pity and support for them even when it is not scientifically supported.

To her credit, Carson avoided that trap. She sought to present the truth-as near as possible- to the people, then let the people make a better-informed decision. She used her text to point out the "corporate irresponsibility, misguided science, and government complicity" in dealing with the natural environment (Lytle 2007, p. 237). In other words, she focused on the evidence and outcomes of inaction and not on placing blame. In our time, the climate crises could be blamed on many factors including companies and governments, but placing blame serves no real purpose since the damage has been done. Like Carson, we need to accept the reality of the crisis and move forward based on the evidence and acting on reasonable solutions.

In order to move forward, we should approach the problem through a collaborative lens and not a controlling one. Williams notes, "The fictions she [Carson] exposes are the myths we have chosen to adopt in our obsession to control nature" (Williams 2008, "One Patriot", p. 18). The obsession can lead into two directions; one of those directions leads to our destruction, and the other leads to a healthier planet and healthier creatures that inhabit it. Carson sought the latter.

"Carson", as Professor of Rhetoric Randy Harris asserts, "wants her readers [ ... ] to feel that insecticides are dangerous, [ ... ] to believe insecticides are dangerous, [ . . and] to know insecticides are dangerous. And to do something about it" (Harris 2000, p. 153). For the climate crisis, writers can create these same feelings in readers, because more tangible and relatable evidence is available than what was available to her. Carson helped readers believe they could do something, and they did as they demanded Federal attention to pesticides and other damaging phenomenon on the environment. Thus, Carson's work provided hope and allowed readers to ask questions, because Carson continually raised questions, sought answers, and never lost hope. She left readers with a sense of purpose and hope that inspired them to become more active in the political and local arena-a staple of some of the best literature (e.g., Upton Sinclair's The Jungle). She also carefully offered the tender underbelly of human life and how it was balanced by its sturdy bones. To illustrate, in her second to last paragraph, she writes, "As crude a weapon as the cave man's club, the chemical barrage has been hurled against the fabric of life-a fabric on the one hand delicate and destructible, on the other miraculously tough and resilient" (Carson 1962, p. 297). It is this resilience that Carson hoped would be fulfilled with the completion of her book, and even with its imperfections, it changed the mindset of a nation, in fact a world, to look more carefully at how we interact with nature.

Carson ushered in an environmental movement that disturbed capitalistic structures that were designed to exploit everything in search of increasing profits. Yet, as readers finish Silent Spring, they are left with the heavy task of deciding what to do next. She provided the lessons in her text and in her response to its reception, which we can apply to climate change. First, she reported the evidence as conclusive in scientific studies and found ways to explain it to readers. Second, Carson mitigated opponents by returning to the results of the studies. Third, she noted how everyone, regardless of previous positions, 
could be part of the solution. Finally, and most importantly, she focused on proactive and preventative policy changes instead of reactive policy changes.

For Carson, the challenge was to convince people of the evidence and its outcomes. To do so, she created the story we read in Silent Spring and incorporated the evidence that allowed people to connect the dots and reach their own conclusions. Mollie K. Murphy explains, "Rather than arguing that an unresolved, ongoing debate justified postponing policy [ ... ] Carson argued that it warranted policy change. She used the fact that the debate was unsettled as leverage to promote precautionary policy" (Murphy 2019, p. 202). We can do the same. Even if the science were not settled (even though, it is), the rationale to do nothing or inexplicably relaxing environmental regulations is not there. Using Carson as an exemplar, the case is clear that taking a preventative and proactive approach can only have positive outcomes. This approach actually responds to the crisis that is getting worse, a crisis that is evidenced more clearly and more tragically year after year. Carson's work reminds us of the importance of literature, our footprint, its impact, and how people can engage with reading it. Without Silent Spring, the climate crisis we are presently in might have been far worse. We must learn and apply its lessons before it is too late. Near the end of Silent Spring, Carson provides us with wisdom and warning; she writes, "The 'control of nature' is a phrase conceived in arrogance, born in the Neanderthal age of biology and philosophy, when it was supposed that nature exists for the convenience of man" (Carson 1962, p. 297). We know now with certainty that the reverse is true.

Funding: The article processing charge (APC) was graciously funded by Literature.

Conflicts of Interest: The author declares no conflict of interest.

\section{References}

Bast, Joseph L., Peter J. Hill, and Richard C. Rue. 1994. Eco-Sanity: A Common-Sense Guide to Environmentalism. Seattle: Madison Books. Carson, Rachel. 1962. Silent Spring. Boston: Houghton.

Ceccarelli, Leah. 2011. Manufactured Scientific Controversy: Science, Rhetoric, and Public Debate. Rhetoric and Public Affairs 14: 195-228. Available online: https:/ / www.jstor.org/stable/41940538 (accessed on 1 June 2021). [CrossRef]

de Steiguer, J. E. 1997. The Age of Environmentalism. New York: McGraw-Hill.

Dunn, James R., and John E. Kinney. 1996. Conservative Environmentalism: Reassessing the Means, Redefining the Ends. Westport: Quorum. Foss, Jeffrey E. 2009. Beyond Environmentalism: A Philosophy of Nature. Hoboken: Wiley.

Freudenburg, William R., Robert Gramling, and Debra J. Davidson. 2008. Scientific Certainty Argumentation Methods (SCAMs): Science and the Politics of Doubt. Sociological Inquiry 78: 2-38. [CrossRef]

Garrard, Greg. 2004. Ecocriticism. New York: Routledge.

Gartner, Carol B. 2000. When Science Writing Becomes Literary Art: The Success of Silent Spring. In And No Birds Sing: Rhetorical Analyses of Rachel Carson's Silent Spring. Edited by Craig Waddell. Carbondale: Southern Illinois UP, pp. 103-25.

Graham, Frank, Jr. 1970. Since Silent Spring. Boston: Houghton.

Harris, Randy. 2000. Other-Words in Silent Spring. In And No Birds Sing: Rhetorical Analyses of Rachel Carson's Silent Spring. Edited by Craig Waddell. Carbondale: Southern Illinois UP, pp. 126-56.

Hynes, H. Patricia. 1989. The Recurring Silent Spring. Oxford: Pergamon.

Killingsworth, M. Jimmie, and Jacqueline S. Palmer. 2000. Silent Spring and Science Fiction: An Essay in the History and Rhetoric of Narrative. In And No Birds Sing: Rhetorical Analyses of Rachel Carson's Silent Spring. Edited by Craig Waddell. Carbondale: Southern Illinois UP, pp. 174-204.

Lear, Linda, ed. 1998. Lost Woods: The Discovered Writing of Rachel Carson. Boston: Beacon.

Lytle, Mark Hamilton. 2007. The Gentle Subversive: Rachel Carson, Silent Spring, and the Rise of the Environmental Movement. Oxford: Oxford UP.

McCay, Mary A. 1993. Rachel Carson. New York: Twayne.

Michaelson, Jay. 2013. Geoengineering and Climate Management: From Marginality to Inevitability. Tulsa Law Review 46: 221-60. Available online: https:/ / digitalcommons.law.utulsa.edu/tlr/vol46/iss2/1 (accessed on 1 June 2021).

Murphy, Mollie K. 2019. Scientific Argument without a Scientific Consensus: Rachel Carson's Rhetorical Strategies in the Silent Spring debates. Argumentation and Advocacy 55: 194-210. [CrossRef]

Peterson, Tarla Rai, and Markus J. Peterson. 2000. Ecology According to Silent Spring's Vision of Progress. In And No Birds Sing: Rhetorical Analyses of Rachel Carson's Silent Spring. Edited by Craig Waddell. Carbondale: Southern Illinois UP, pp. 73-102.

Sideris, Lisa H., and Kathleen Dean Moore. 2008. Introduction. In Rachel Carson: Legacy and Challenge. Edited by Lisa H. Sideris and Kathleen Dean Moore. Albany: SUNY, pp. 1-13. 
Waddell, Craig. 2000. The Reception of Silent Spring: An Introduction. In And No Birds Sing: Rhetorical Analyses of Rachel Carson's Silent Spring. Edited by Craig Waddell. Carbondale: Southern Illinois UP, pp. 1-16.

White, Elwyn Brooks. 2008. Sootfall and Fallout. In American Earth: Environmental Writing since Thoreau. Edited by Bill McKibben. New York: Library, pp. 327-36.

Williams, Terry Tempest. 2007. The Moral Courage of Rachel Carson. In Courage for the Earth: Writers, Scientists, and Activists Celebrate the Life and Writing of Rachel Carson. Edited by Peter Matthiessen. Boston: Houghton Mifflin, pp. 129-46.

Williams, Terry Tempest. 2008. One Patriot. In Rachel Carson: Legacy and Challenge. Edited by Lisa H. Sideris and Kathleen Dean Moore. Albany: SUNY, pp. 16-28. 